\title{
Lympholeukemia in madai Pagrus major in Japan
}

\author{
Teruo Miyazaki ${ }^{1, *}$, Yukako Asai $^{2}$, Tatsuya Kobayashi ${ }^{1}$, Masato Miyata ${ }^{1}$ \\ ${ }^{1}$ Faculty of Bioresources, Mie University, 1515 Kamihama, Tsu, Mie 514-8507, Japan \\ ${ }^{2}$ Faculty of Medicine, Nagoya University, Tsurumai, Showa-ku, Nagoya, Aichi, Japan
}

\begin{abstract}
Lympholeukemia has been occurring to an epizootic extent with mass mortality in 1 and 2 yr old madai (= Japanese red sea bream) Pagrus major in the winter season (October-May) in the western regions of Japan since 1975. Diseased fish displayed severe anemia and markedly increased numbers of neoplastic lymphocytoid and lymphoblastoid cells in the blood. Neoplastic cells originated in the splenic lymphatic cells and systemically caused severe metastatic lesions in the heart, liver, kidney, digestive tracts, gills and the lateral musculature. Electron microscopy revealed adeno-like viral particles ( 78 to $83 \mathrm{~nm}$ in diameter) in the nucleus of lymphoblastoid cells which appeared in the early prevalent stage but no viral particles in the lymphocytoid cells or plasmacytoid cells, which subsequently increased in number. In this paper, we describe light and electron microscopic features of neoplasms and neoplastic cells.
\end{abstract}

KEY WORDS: Lympholeukemia A Adeno-like virus Red Sea bream

\section{INTRODUCTION}

Lymphatic neoplasia such as lymphoma, lymphosarcoma, lympholeukemia and plasmacytoid leukemia have been found in various fish species. There have been occurrences of lymphosarcomas of wild esocid fishes Esox spp. which have assumed epizootic proportions (Mulcahy 1976, Papas et al. 1976. Sonstegard 1976, Thompson 1982). Based on transmission trials and the demonstration of reverse transcriptase activity, an oncogenic retrovirus was suggested to cause the esocid neoplasm (Papas et al. 1976, 1977). Plasmacytoid leukemia has caused mass mortalities in cultured chinook salmon Oncorhynchus tshawytscha and was revealed to be the retroviral etiology (Kent \& Dawe 1990, 1993, Kent et al. 1990, Eaton \& Kent 1992, Eaton et al. 1993). Moreover, lymphatic neoplasia have been found to occur spontaneously in medaka (= Japanese killifish) Oryzias latipes (Kubota et al. 1982), tilapia Sarotherodon spilurus (Haller \& Roberts 1980), grayling Thymallus thymallus (Hoffman et al. 1988) and salmonid fishes (Dunbar 1969, McArdle \& Roberts 1974, Roald \& Hastein 1979, Bernstein 1984, Warr et al.

•E-mail:miyazaki@bio.mie-u.ac.jp
1984, Bruno \& Smail 1998). Except for the lymphomas of tilapia and grayling, which have a hematopoietic origin, lymphosarcomas of killifish and salmonids usually have a thymic origin. Thus, although lymphatic neoplasia have been found in various fish species, the putative etiological agent has been unproven except for plasmacytoid leukemia.

Since 1975 lympholeukemia has been occurring in 1 and 2 yr old madai (= Japanese red sea bream: Pagrus major), accompanyied by mass mortality in the winter season (October-May) in the western regions of Japan. Tumorous madai always occurred to an epizootic extent. Within a small bay, diseased fish that were reared in several net cages close to each other experienced mass mortality while fish in far distant cages were unaffected. The tumorous fish displayed severe anemia and markedly increased numbers of lymphocytoid and lymphoblastoid cells in the blood, indicating lympholeukemia. The tumorous fish appeared in the early winter when the water temperature dropped below $20^{\circ} \mathrm{C}$, and were present until mid-spring of the following year, when the water temperature rose above $20^{\circ} \mathrm{C}$. During the prevalent period, the types of neoplastic cells present varied with the season.

In the present study, we performed histopathological and electron microscopic examinations of the tumor- 
ous fish. We found evidence of adeno-like viral particles within the neoplastic cells. In this paper, we describe histopathological signs and features of neoplastic cells, and identify a putative virus by electron microscopy.

\section{MATERIALS AND METHODS}

Around 80 tumorous madai ( 1 and 2 yr old) were collected at various culturing sites in the western regions of Japan from 1975 to 1993. Tumorous fish were not present every year and so diseased fish were collected only when tumors occurred among farmed fish experiencing mass mortality. Tumorous fish collected until 1991 were processed for histopathological examinations. In 1992, when tumorous fish were found in a 1 yr old population in Mie Prefecture, we collected 5 each of the diseased fish in November 1992, January and February 1993. Additionally, 6 diseased fish were collected again from a 1 yr old population in a different region in October 1993. These tumorous fish collected between 1992 and 1993 were mainly used for electron microscopy and histological examinations.

After external and internal examinations, the tissues of spleen, anterior and posterior kidneys, liver, heart, gills, thymi, stomach, intestine, skin and lateral musculature, brain and eye balls were dissected and fixed in $10 \%$ phosphate buffered formalin for histological studies. The fixed tissues were prepared according to standard techniques and stained with hematoxylin \& eosin (H\&E), Azan, Giemsa and PAS. Pieces of the spleen, kidney, liver and heart were fixed in $70 \%$ Karnovsky solution, postfixed in $1 \% \mathrm{OsO}_{4}$ and processed for transmission electron microscopy (TEM), and prefixed pieces of the spleen were processed for scanning electron microscopy (SEM) according to standard techniques. Because histological examination revealed the severe metastases of neoplastic cells, in order to determine a leukemic state, the blood was taken with a $1 \mathrm{ml}$ syringe from the Cuvier duct of tumorous fish collected between 1992 and 1993. Blood smears were made on slide glasses and stained with Giemsa.

\section{RESULTS}

\section{External and internal examinations}

Lympholeukemic madai mostly occurred among 1 yr old populations and sometimes among 2 yr old ones. This outbreak of tumors began in early winter and lasted until spring of the next year, and throughout the prevalent period, mass mortality occurred (around 20 to $30 \%$ of the population). Tumorous fish showed good growth in early winter whereas the bodies of diseased fish were thinner from mid-winter to spring. All tumorous fish showed a markedly discolored body coloration, which is indicative of severe anemia, and sometimes skin erosion and ulceration with slight hemorrhage. Some tumorous fish displayed a swollen abdomen due to the accumulation of ascitic fluid. Ali spleens were markedly swollen and discolored. The liver was usually swollen and either entirely discolored or partly green. The anterior and posterior kidney, the heart, the stomach and the intestine were also sometimes swollen but less frequently so than the liver (Fig. 1A). The gills showed marked discoloration due to anemia, and gill filaments were somewhat swollen. The thymi on the gill cavities never protruded into the cavity and most lioked normal.

\section{Electron microscopic examinations}

EM examination was performed to confirm the features of neoplastic cells that appeared in the spleen, kidney, heart and liver tissues. In comparison with the morphology of human lymphatic cells (Ross et al. 1989), neoplastic cells were made up of lymphoblastoid cells, lymphocytoid cells and plasmacytoid cells (Fig. 1B). In TEM, lymphoblastoid cells were large cells which had a wide cytoplasm containing welldeveloped rough-surfaced endoplasmic reticula (rER), abundant free ribosomes, large numbers of mitochondria and vacuoles, and a smooth plasma membrane with some protuberances. Their nuclei were quite large, had a round or irregular, round shape and contained prominent nucleoli. In the nucleus, heterochromatin was abundant and thickly deposited on the inner surface of the nuclear membrane while fine granular euchromatin occupied the central area (Fig. 2A,B). Most of the lymphoblastoid cells displayed many viruslike particles in the nucleus but no evidence of virions in the cytoplasm, which appeared in the spleen as well as in metastatic lesions in the hematopoietic tissue, liver and heart. The virus-like particles had a round or hexagonal shape ( 78 to $83 \mathrm{~nm}$ in diameter) with fibrous protrusion-like structures on the capsid (Fig. 2C) which resembled the morphology of adennviruses (Murphy et al. 1995). These virus-bearing cells were apparently observed in the tumorous fish collected in October and November of different years and from 2 different regions. These lymphoblastoid cells were markedly fewer, and virus-bearing cells were no longer evident in January of the next year In contrast, we were unable to prove that viral particles were present in the blast cells of the erythrocytes and the granulocytes in the hematopoietic tissue throughout the period of prevalence (Fig. 2D) 
Fig. 1 Pagrus major. (A) A dissected view of a tumorous madai caught in November. The spleen (arrow) is markedly swollen. The kidney $(k)$ is enlarged and protrudes into the abdominal cavity. The gill filaments and liver (1) are swollen and discolored due to anemia. (B) SEM photograph of the spleen of a tumorous fish caught in February. A small number of large lymphoblastoid cells and large numbers of lymphocytoid cells with cytoplasmic protuberances and plasmacytoid round-shaped cells are present. Biconcave disc-shaped cells are erythrocytes. Scale bar $=10 \mu \mathrm{m}$
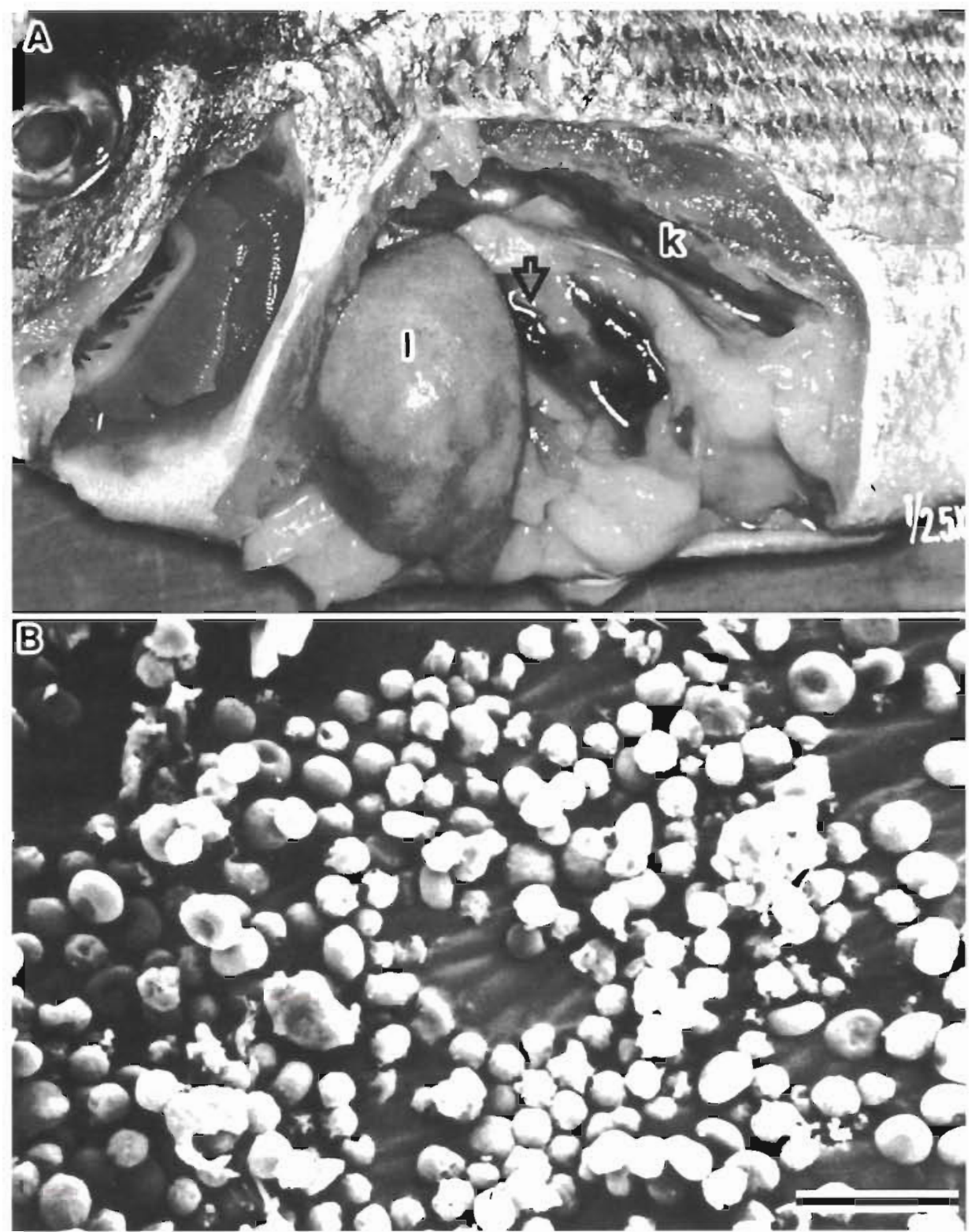

Lymphocytoid cells had a narrow cytoplasm with many protuberances around a round or cleft nucleus with dominant heterochromatin and a prominent nucleolus (Fig 3A to D). The cytoplasm contained many vesicles and less abundant free ribosomes, a small number of mitochondria, and almost no rER. The presence of viral particles could not be proven in the nucleus or in the cytoplasm. Lymphocytoid cells appeared in October and November, and most abundantly in January and February.

Plasmacytoid cells frequently appeared with lymphocytoid cells in February but in rather lower numbers than lymphocytoid cells. They were round shaped and had an irregularly shaped nucleus showing hyperchromatosis on the inner surface of the nuclear mem- brane, and a moderately wide cytoplasm containing well-developed rER, markedly abundant free ribosomes, and small numbers of mitochondria (Fig, 3D,E). No viral particles were present in the nucleus.

\section{Blood smear and histopathological examinations}

The blood taken from specimens contained huge numbers of neoplastic cells, such as lymphoblastoid cells, lymphocytoid cells and plasmacytoid cells, which were classified according to the results obtained with in situ TEM described above. In most of the tumorous fish, neoplastic cells outnumbered erythrocytes, that were mostly immature and had a slight basophilic 

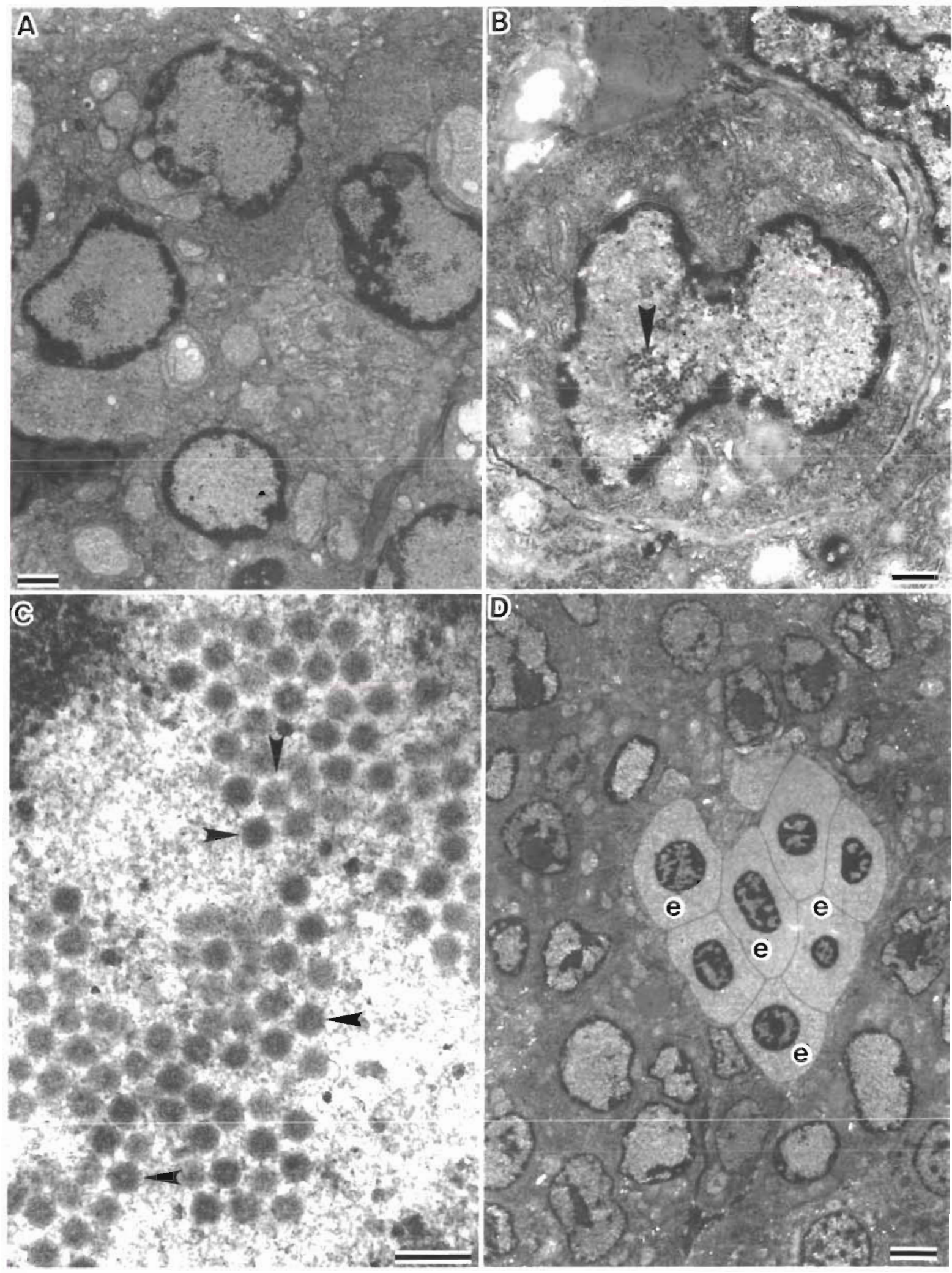

Fig. 2. Pagrus major. (A to D) TEM photographs of neoplastic cells of tumorous fish caught in November. (A) In the swollen spleen, many lymphoblastoid cells are present and most of them contain virus-like particles in the nucleus. Scale bar $=1000 \mathrm{~nm}$. (B) Lymphoblastord cell containing viral particles (arrowhead) in the nucleus Scale bax $=600 \mathrm{~nm}$. (C) A high power view of virus-like particles in a nucleus of a lymphoblastold cell The vira] morphology resembles that of adenovirus. Arrowsheads point to particles with distinct fibers while fibers of most of the particles are less apparent because the section is ultra-thin. Scale bar $=160 \mathrm{~nm}$. (D) In the hematopoietic tissue, hematopoletic blast cells display no viral particles in nucle e immature erythrocytes. Scale bar $=2500$ nm 

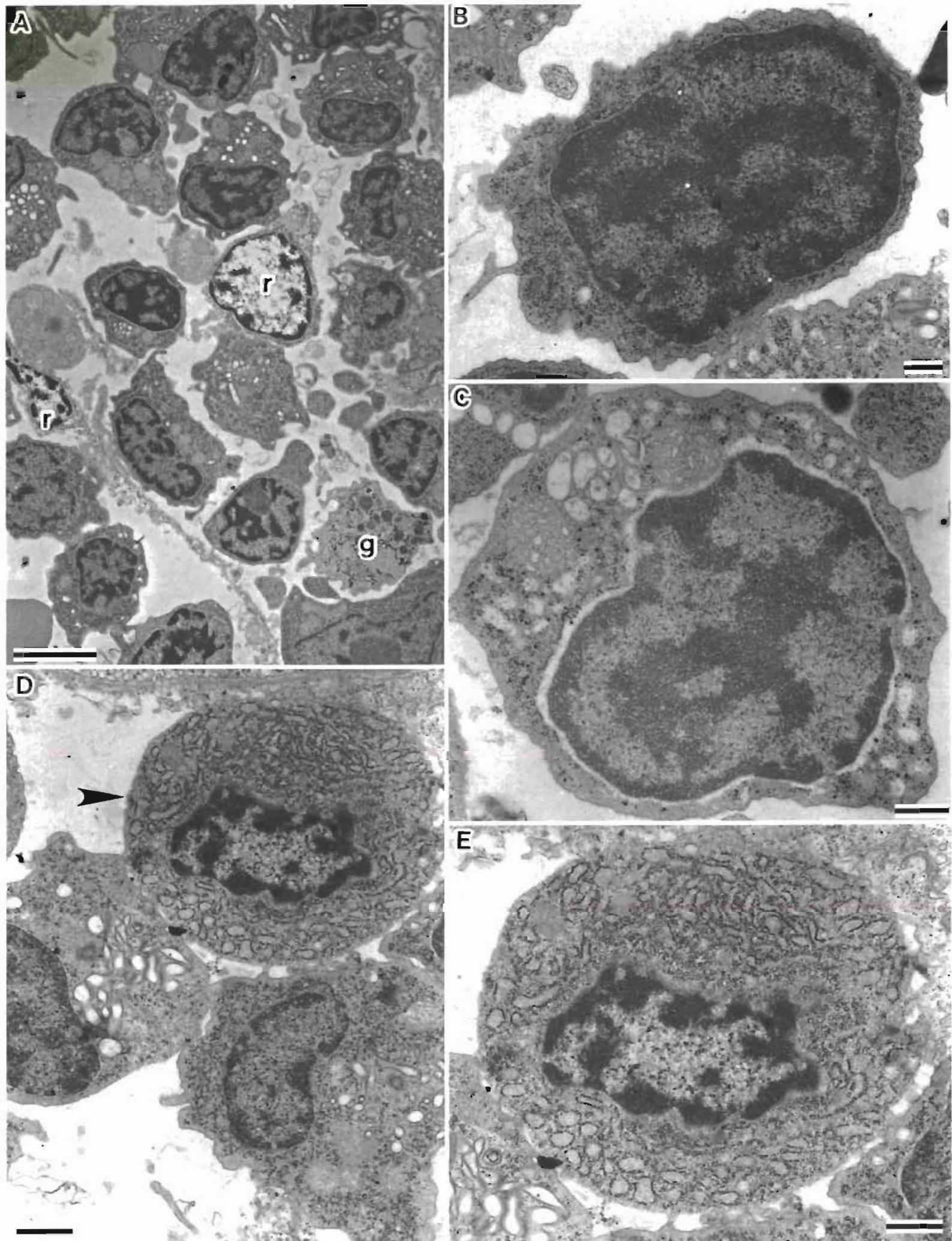

Fig. 3. Pagrus major. (A to E) TEM photographs of neoplastic cells of tumorous fish caught in February. (A) Many lymphocytoid cells proliferate in the spleen. g: granulocyte. $\mathrm{r}$ : reticular cells. Scale bar $=4000 \mathrm{~nm}$. (B) A high power view of a lymphocytoid cell Scale bar $=500 \mathrm{~nm}$. (C) A high power view of a lymphocytoid cell which has abundant vesicles and a few mitachondria. Scale bar $=500 \mathrm{~nm}$. (D) A plasmacytoid cell (arrowhead) is present among the lymphocytoid cells within a metastatic lesion in the hematopoietic tissue. Scale bar $=1000 \mathrm{~nm}$. (E) Detail of a plasmacytoid cell. It has abundant $\mathrm{rER}$ and free ribosomes in the cytoplasm. Scale bar $=880 \mathrm{~nm}$ 
cytoplasm. The proportion of each neoplastic cell type which occurred varied with the progression of the disease. Because blood was taken from the tumorous fish on a small boat, blood cell counts could not be done and, therefore, the percentage of each blood cell type was not determined. Although the percentage of neoplastic cells was therefore not revealed, lymphoblastoid cells and lymphocytoid cells significantly increased in number in most tumorous fish caught in October and November (Fig. 4A). Lymphoblastoid cells were large in size and had a basophilic cytoplasm and a large nucleus. Lymphocytoid cells had a narrow, less basophilic cytoplasm with many protuberances and a condensed nucleus, and some of these cells had

azurophilic granules in the cytoplasm. In the mid-and late stages of the prevalence, lymphocytoid cells and plasmacytoid cells were more predominant than lymphoblastoid cells (Fig. 4B). Plasmacytoid cells were round shaped, and had a basophilic cytoplasm and a perinuclear halo.

In histological examinations, the most severe neoplastic proliferation was observed in the swollen spleen. In the early stage of the outbreak, huge numbers of lymphoblastoid cells proliferated and diffused along with many mitotic figures throughout the pulps (Fig. 5A), and migrated into sheathed arteries and central veins. Such a severe proliferation of neoplastic cells usually caused stasis in the pulpic sinusoid. The predominant cell type was variable during the prevalent period as delermined

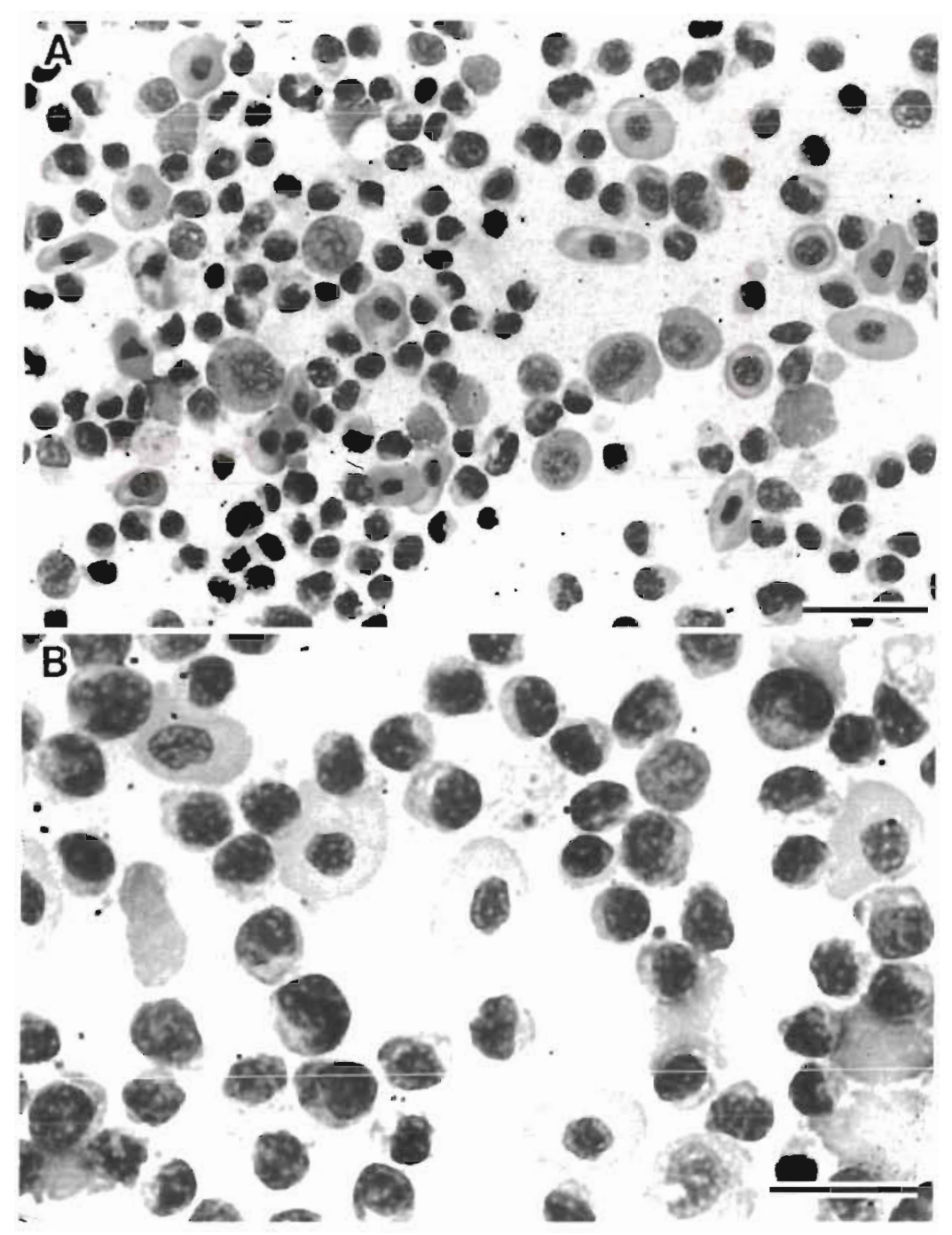

Fig. 4. Pagrus major. (A) Blood smear from a tumorous fish collected in November. A large number of lymphoblastoid and lymphocytoid cells appear. Giemsa. Scale bar $=100 \mu \mathrm{m}$. (B) Blood smear from a tumorous fish collected in February. A large number of lymphocytoid cells and round-shaped plasmacytoid cells are present. Neoplastic cells outnumber erythrocytes. Giemsa. Scale bar $=200 \mu \mathrm{m}$ in the TEM examinations. In some diseased fish taken in the Iate prevalent stage, neoplastic cells had moved out of the tissues in the spleen, where fibrous meshwork containing necrotized splenocyte remained.

The neoplastic cells had a remarkable propensity to metastasize and so metastatic lesions formed all over the body except the thymi. In the liver, neoplastic cells formed many metastatic lesions around the portal triads and around intrahepatic masses of the pancreatic acinar cells (Fig. 5B), Neoplastic cells also migrated into the sinusoid and formed cellular foci penetrating hepatic parenchyma and bile canaliculi throughout the liver in severe cases. Hepatocytes were usually atrophied, showing decreasing amounts of fat and glycogen. Hepatocytes beside or included in the neoplastic cellular foci were pressed and atrophied. In the green-colored lesions, hepatocytes underwent vacuolar degeneration between neoplastic cells. In the posterior kidney, neoplastic cells invaded renal tubular epithelia and lumen, glomerular capillaries and the urinary space (Fig. 5C). When neoplastic cells penetrated hematopoietic tissues either focally or diffusely, nephrons were present distantly spaces from each other. An important finding was that in some diseased fish, hematopoietic tissues did not appear to be affected although the spleen displayed an obvious proliferation of neoplastic cells. In these cases, the kidney did not show swelling in internal examinations. 



Fig. 5. Pagrus major. (A) Spleen of a tumorous fish caught in November. Lymphoblastoid cells proliferate extensively in the pulps and migrate into a central vein. H\&E. Scale bar $=100 \mu \mathrm{m}$. (B) Metastatic lesions in the liver of the same fish. Huge numbers of neoplastic cells have invaded the area around the portal triad and the parenchyma. Affected hepatocytes (h) and pancreatic acinar cells (p) had been pressed, and were atrophied. b: bile ducts. H\&E. Scale bar $=100 \mu \mathrm{m}$. (C) Kidney of a tumorous fish caught in February. Neoplastic cells migrate into the glomerular capillaries, the urinary space and tubular lumens. They also invade the hematopoietic tissue. H\&E. Scale bar $=50 \mu \mathrm{m}$. (D) Metastatic lesions in an auricle of a tumorous fish caught in October. Huge numbers of neoplastic cells have invaded the myocardium and the area between the endocardium and muscle layers forming many cellular foci. $\mathrm{H} \& \mathrm{E}$. Scale bar $=100 \mu \mathrm{m}$ 
In the heart, neoplastic cells were present in large numbers within the lumens and formed many metastatic lesions in the endocardium, myocardium and epicardium of the auricle (Fig. 5D) as well as the ventricle. Cardiac muscle fibers enclosed with the neoplastic cellular foci showed atrophy and necrosis. In the gills, neoplastic cells invaded lamellar capillaries and epithelia, where they formed cellular foci. Neoplastic cells also invaded and diffused throughout the connective tissues of gill filaments and inter-lamellar epithelia. Formations of metastatic lesions appeared in various regions in the stomach and intestine. Neoplastic cells penetrated connective tissues of the lateral musculature, the subcutaneous adipose tissue, the dermis, and the retina and choroidal membrane of the eyeballs. Although the lesions were small, neoplastic cells invaded tissues in the brain. The thymi usually did not appear to be involved.

\section{DISCUSSION}

In the present studies on madai lympholeukemia, viral particles appeared in the nucleus of neoplastic lymphoblastoid cells. The virus-bearing lymphoblastoid cells predominantly appeared only in the early stage of the outbreak. Thus, the timing of the appearance of viral particles was limited. Similarly, in plasmacytoid leukemia of chinook salmon the etiological retrovirus usually does not appear around the neoplastic plasmablasts (Kent et al 1990, Eaton \& Kent 1992). The virus-bearing lymphoblastoid cells were found in the tumorous fish that were collected in different years and at different locations. This fact indicates that the putative virus would be the etiology of madai lympholeukemia. The intranuclear viral particles resembled the morphology of adenovirus (Murphy et al. 1995). Indeed, mammalian adenoviruses have been proposed to transform artificially infected cells (Yamashita et al. 1992). On the other hand, some viruses belonging to Herpesviridae have been also known to be oncogenic (Yamashita et al. 1992). Especially the Epstein-Barr virus is proposed to infect and transform human Blymphocytes (Shimizu \& Takata 1992). Therefore, we should not exclude the possibility that intranuclear virai particies of the iymphobiastoid ceils are nucieocapsids of a kind of herpesvirus, although we could not find any enveloped virions in their cytoplasms in the present study. The neoplastic lymphoblastoid cells appear to have been transformed from splenic lymphoblasts that were infected with the putative virus because there was no evidence for viral infection in the hematopoietic blast cells in the kidney or in blast cells in the thymi even in the early stage of the outbreak. In the tumorous fish, formations of metastatic lesions were very severe, and would be expected to cause functional disturbances of the affected organs and mortalities of tumorous fish. The severity of the metastasis indicates that madai lympholeukemia is apparently malignant. The mortality of tumorous fish would cause horizontal dissemination of the putative virus, resulting in an epizootic.

On the other hand, in the mid-and late stages of the prevalent period, lymphocytoid cells and plasmacytoid cells were predominant, and virus-bearing lymphoblastoid cells had disappeared. Neoplastic lymphoblastoid cells would differentiate into lymphocytoid cells. Plasmacytoid cells appeared to be derived from neoplastic lymphocytoid cells. This derivation would depend on the aberrant character of the neoplastic cells, probably without the involvement of an immunoreaction although the possibility that the plasmacytoid cells were derived from an immuno-reaction against the putative adeno-like virus cannot be ruled out completely. The derivation of plasmacytoid cells seems to support the theory that madai lympholeukemia originates in B-lymphatic cells in the spleen. In contrast to madai lympholeukemia, plasmacytoid leukemia of chinook salmon mainly consisted of plasmablasts and these do not appear to differentiate into plasma cells (Kent et al. 1990). The electron microscopic features of the plasmablasts resembled those of plasmacytoid cells of madai lympholeukemia rather than those of the lymphoblastoid cells because of the abundant rER. Similarly, lymphatic tumors of the other fishes usually consisted of blast-type cells. The active differentiation of neoplastic lymphoblastoid cells appears to be characteristic of madai lympholeukemia.

We recently succeeded in establishing a cell line which was made up of lymphoblast-like cells and lymphocyte-like cells which were the same as those in tumorous fish. Therefore, we propose that the cell line would be a derivative of neoplastic cells (Miyata \& Miyazaki umpubl. data). Cell lines from tumorous tissues have successfully been established in northern pike lymphoma (Thompson 1982) and plasmacytoid leukemia of chinook salmon, from which an etiological retrovirus could be isolated (Eaton et al. 1993). We are presently investigating cultured cells to determine whether the cultured celis have oncogenes or viral genoms and whether they can manitest particles of the putative adeno-like virus. Our next papers will report these results including the characteristics of the cultured cells.

\section{LITERATURE CITED}

Bernstein JW (1984) Leukaemic lymphosarcoma in a hatchery-reared rainbow trout, Salmo gairdneri Richardson. J Fish Dis 7:83-86 
Bruno DW, Smail DA (1998) Lymphoma in farmed rainbow trout, Oncorhynchus mykiss (Walbaum): a case study. J Fish Dis 21:381-386

Dunbar CE (1969) Lymphosarcoma of possible thymic origin in salmonid fishes. Natl Cancer Inst Monogr 31:167-171

Eaton WD, Kent ML (1992) A retrovirus in chinook salmon (Oncorhynchus tshawytscha) in plasmacytoid leukemia and evidence for the etiology of the disease. Cancer Res $52: 6496-6500$

Eaton WD, Folkins B, Bagshaw J, Traxler G, Kent ML (1993) Isolation of a retrovirus from two fish cell lines developed from chinook salmon (Oncorhynchus tshawytscha) with plasmacytoid leukemia. J Gen Virol 74:2299-2302

Haller RD, Roberts RJ (1980) Dual neoplasia in a specimen of Satherodon spilurus spilurus (Gunther) (Tilapia spilurus). J Fish Dis 3:63-66

Hoffmann RW, Fisher-Scherl TH, Pfeil-Putzien C (1988) Lymphosarcoma in a wild grayling, Thymallus thymallus $\mathrm{L}$. $\mathrm{J}$ Fish Dis 11:267-270

Kent ML, Dawe SC (1990) Experimental transmission of a plasmacytoid leukemia of chinook salmon, Oncorhynchus tshawytscha. Cancer Res 50:5679-5681

Kent ML, Dawe SC (1993) Further evidence for a viral etiology in plasmacytoid leukemia of chinook salmon, Oncorhynchus tshawytscha. Dis Aquat Org 15:115-121

Kent ML, Groff JM, Traxler GS, Zinkl JG, Bagshaw JW (1990) Plasmacytoid leukemia in sea-water reared chinook salmon Oncorhynchus tshawytscha. Dis Aquat Org 8:199-209

Kubota SS, Miyazaki T, Egusa S (1982) Color atlas of fish histopathology. Shin-Suisan-Shinbunsha, Tokyo

McArdle JF, Roberts RJ (1974) Bilateral hyperplasia of the thymus in rainbow trout (Salmo gairdneri). J Fish Res

Editorial responsibility: Jo-Ann Leong,

Corvallis, Oregon, USA
Board Can 31:1537-1539

Mulcahy MF (1976) Epizootiological studies of lymphomas in northern pike in Ireland. Prog Exp Tum Res 20:129-140

Murphy FA, Fauquet CM, Bishop DHL, Ghabrial SA, Jarvis AW, Martelli GP, Mayo MA, Summers MD (1995) Virus taxonomy. Springer-Verlag, New York

Papas TS, Dahlberg JE, Sonstegard RA (1976) Type C virus in lymphosarcoma in northern pike (Esox lucius). Nature 261:506-508

Papas TS, Pry TW, Schafer MP, Sonstegard RA (1977) Presence of DNA polymerase in pike (Esox lucius). Can Res 37 $3214-3217$

Roald SO, Hastein T (1979) Lymphosarcoma in an Atlantic salmon Salmo salar L. J Fish Dis 2:249-251

Ross MH, Keith EJ, Romrell LJ (1989) Histology, 2nd edn. Williams \& Wilkins, Baltimore

Shimizu N, Takata K (1992) Epstein-Barr virus; gene expression and replication. Protein Nucleic Acid Enzyme 37 : 200-209 (in Japanese)

Sonstegard RA (1976) Studies of the etiology and epizootiology of lymphosarcoma in Esox (Esox lucius L and Esox masquinongy). Prog Exp Tum Res 20:141-155

Thompson JS (1982) An epizootic of lymphoma in northern pike, Esox lucius L., from the Aland Islands of Finland J Fish Dis 5:1-11

Warr BR, Griffin BR, Anderson DP, McAllister PE, Lidgerding $B$, Smith CE (1984) A lymphosarcoma of thymic origin in rainbow trout, Salmo gairdneri Richardson. J Fish Dis 7 $73-82$

Yamashita T, Sawada K, Hujinaga M (1992) Oncogenicity of DNA viruses. Protein Nucleic Acid Enzyme 37:506-519 (in Japanese)

Submitted: June 30,1999; Accepted: December 8, 1999 Proofs received from author(s): February 28, 2000 